\title{
Implementasi Metode Market Basket Analysis Pada Sistem Penjualan Dan Pemasaran Pada Butik Nazwa Fashion
}

\author{
Tika Wati ${ }^{1}$, Vivi Sahvitri ${ }^{2}$, Kiky Rizky Nova Wardani ${ }^{3}$ \\ 1,2Information System Departement, Bina Darma University, Palembang, Indonesia \\ ${ }^{2}$ Vocational Departement , Bina Darma University, Palembang, Indonesia \\ Email: 1'tikawati1996@gmail.com, ${ }^{2}$ vivi_sahfitri@binadarma.ac.id, ${ }^{3}$ kikirnwardani@gmail.com
}

\begin{abstract}
Nazwa Fashion Boutique Shop is a shop that sells various kinds of women's fashion such as clothes, pants, skirts and hijab clothing with various brands and prices. The Nazwa Fashion Boutique Shop is located at Jalan D.I Panjaiatan No.1 Kelurahan 16 ULU Kec. SU2 RT.32 RW.10 which has been established since 2013 or less than 5 years. During the sales process at the Nazwa Boutique Shop Mode is still done manually, ie prospective buyers come directly at the Nazwa Mode Boutique Shop to buy products Clothing available on the storefront store. This is less effective because consumers incur considerable costs. To overcome this problem, the author tries to provide a solution to build media sales transactions online, the online sales transaction media is to build an E-Commerce website using the Basket Market Analysis method as one of the media for sales and promotions that is useful to help companies market the products it sells and is targeted to manage again get income and increase the stock of goods in the warehouse. In addition, the existence of online transactions can make it easier for consumers to choose and order products they want so they can increase company profits.
\end{abstract}

Keywords: e-commerce, Nazwa Fashion, market basket analysis

\section{PENDAHULUAN}

Teknologi informasi dalam suatu aktivitas bisnis merupakan hal yang cukup penting, salah satu bentuk aktivitas bisnis yang melibatkan teknologi informasi yaitu sistem pelayanaan berbasis online. Penggunaan teknologi informasi tersebut dapat memudahkan bisnis tersebut dalam melaksanakan pekerjaanya, maka saat ini hampir setiap bisnis banyak sekali menggunakan website sebagai sarana untuk melakukan jual/beli atau dalam kegiatan penjualan dan pemasaran secara online. Website tidak hanya menampilkan berita atau informasi saja, saat ini dalam website banyak fasilitas seperti penjualan online, pemesanan barang/jasa yang dapat memudahkan para calon 
konsumen dalam melakukan pembelian suatu barang. Penggunaan sistem penjualan secara online selain memberikan informasi, juga akan mempermudah dalam mengelola jumlah barang, harga barang dan melakukan transaksi (Yenti: 2015).

Butik Nazwa Fashion adalah sebuah toko yang menjual berbagai macam Fashion wanita dengan berbagai merek maupun harga seperti: atasan remaja, gamis, celana, rok, pakaian syar'i, jilbab, aksesoris jilbab dll. Butik Nazwa fashion beralamatkan di Jalan D.I Panjaiatan No.1 Kelurahan 16 ULU Kec. S.U.2 RT.32 RW.10 yang telah berdiri sejak tahun 2013 atau kurang lebih 5 tahun. Selama ini proses penjualan pada Butik Nazwa Fashion masih dilakukan secara manual yakni calon pembeli mendatangi langsung pada Nazwa Fashion untuk membeli produk fashion wanita yang tersedia pada etalase butik Hal ini dirasakan kurang efektif dikarenakan konsumen berpotensi mengeluarkan biaya yang cukup besar.

Permasalahan lainnya, sistem penjualan dengan cara ini membutuhkan waktu yang lama dalam proses penjualan produk fashion pada butik Nazwa tersebut, karena kurangnya informasi dan rekomendasi barang yang tepat untuk calon pembeli. Selain itu, kebutuhan mengenai prediksi keterikatan suatu produk terhadap produk lainnya sangat bermanfaat dalam penawaran suatu produk kepada konsumen. Seorang konsumen akan menggunakan waktunya lebih efektif apabila produk yang ditawarkan sesuai dengan kebutuhannya saat itu. Sebaliknya konsumen dapat merasa kesal apabila mendapat tawaran produk yang saat itu tidak dibutuhkannya.

Market Basket Analysis adalah salah satu cara yang digunakan untuk menganalisis data penjualan dari suatu perusahaan. Proses ini menganalisis buying habits konsumen dengan menemukan asosiasi antar item-item yang berbeda yang diletakkan konsumen dalam shopping basket (keranjang belanja). Hasil yang didapatkan ini nantinya dapat dimanfaatkan oleh perusahaan retail seperti toko atau swalayan untuk mengembangkan strategi pemasaran dengan melihat item-item mana saja yang sering dibeli secara bersamaan oleh konsumen. (Han dan Kamber: 2001).

Untuk mengatasi permasalahan tersebut, maka penulis mencoba memberikan solusi untuk membangun media transaksi penjualan secara online, media transaksi penjualan online tersebut yaitu membangun website E-Commerce dengan menerapkan metode Market Basket Analysis sebagai salah satu media penjualan dan promosi yang berguna untuk membantu perusahaan dalam memasarkan produk yang dijualnya dan sebagai acuan untuk memanajemen ulang persentase pemasukan dan pengeluaran stok barang yang ada pada 
gudang. Selain itu, dengan adanya transaksi secara online dapat mempermudah konsumen untuk memilih dan memesan produk yang diinginkannya sehingga dapat meningkatkan laba perusahaan. Berdasarkan uraian permasalahan diatas penulis melakukan penelitian judul "Implementasi Metode Market Basket Analysis pada Sistem Penjualan dan Pemasaran pada Butik Nazwa Fashion".

\section{METODOLOGI PENELITIAN}

\subsection{Metode Pengembangan Web Engginering}

Adapun tahapan yang dilakukan penulis dalam merancang dan membangun website e-commerce menggunakan pengembangan sistem rekayasa web (web engineering). Rekayasa web mengadaptasi rekayasa perangkat lunak dalam hal konsep dasar yang menekankan pada aktifitas teknis dan manajemen. Metode atau model rekayasa web melingkupi aktifitas-aktifitas sebagai berikut:

\subsubsection{Formulasi}

Tahapan formulasi adalah tahapan dimana dirumuskannya tujuan dari pembangunan sistem serta menentukan batasan-batasan pada sistem penjualan berbasis online pada Butik Nazwa Fashion menggunakan metode Market Basket Analysis (MBA). Berikut Tujuan dari sistem yang akan dibangun dapat dibedakan menjadi dua kategori, yaitu :

a) Tujuan Yang Bersifat Informatif

Menyediakan suatu informasi tertentu kepada pengguna mengenai sistem penjualan berbasis online pada Butik Nazwa Fashion menggunakan metode Market Basket Analysis (MBA) berupa informasi produk yang dapat diakses melalui media internet.

b) Tujuan Yang Bersifat Fungsional

Sistem penjualan berbasis online pada Butik Nazwa Fashion menggunakan metode Market Basket Analysis (MBA) yang akan dibangun secara fungsional mempunyai tujuan dan kemampuan untuk melakukan suatu fungsi yang dibutuhkan pengguna, misal dengan menggunakan aplikasi tersebut seorang pelanggan dapat memperoleh informasi produk serta melakukan pembelian hanya melalui website saja tanpa harus mendatangi toko, dan bagi pemilik toko dapat mengetahui analisis mengenai tingkat minat pelanggan terhadap suatu produk dikarenakan menghadirkan perhitungan analisis MBA. 


\subsubsection{Analisis}

Analisis merupakan tahapan awal dalam perancangan sistem untuk mengidentifikasi masalah dan kebutuhan-kebutuhan dalam pembangunan sebuah sistem, agar diperoleh hasil yang maksimal dan keakuratan aplikasi dalam proses transaksi yang berjalan. Kebutuhan sistem aplikasi ini yaitu, data input dan data output. Data input sistem berupa informasi pengolahan data penjualan, sedangkan data output sistem adalah informasi berupa laporan transaksi yang sedang berjalan, serta analisis mengggunakan metode Market Basket Analysis (MBA).

\subsubsection{Analisis Kebutuhan Sistem}

Sub bab analisis kebutuhan sistem pada pembangunan sistem penjualan berbasis online pada Butik Nazwa Fashion menggunakan metode Market Basket Analysis (MBA) menjelaskan mengenai data masukkan dan data keluaran, serta perangkat keras dan perangkat lunak yang dibutuhkan. Data merupakan informasi baik berupa teks, gambar, maupun video. Data dalam sistem penjualan berbasis online pada Butik Nazwa Fashion menggunakan metode Market Basket Analysis (MBA) digunakan dalam dua kebutuhan yaitu:

a. Kebutuhan Data Masukkan, Kebutuhan data masukkan pada sistem ini dibedakan menjadi dua, yaitu:

1) Data yang dimasukkan oleh administrator, terdiri dari Data sistem otoritas penggunaan aplikasi, data penggunaan aplikasi, data kategori produk, produk, data penjualan, dan data laporan analisis MBA.

2) Data yang dimasukkan oleh Pelanggan yaitu login sistem dan proses pemesanan barang.

b. Kebutuhan Data Keluaran, Kebutuhan data keluaran dari sistem ini adalah informasi berupa laporan transaksi penjualan serta laporan analisis penjualan menggunakan metode Market Basket Analysis $(M B A)$.

\subsection{Association Rule}

Menurut Han dan Kamber (2001), Association rule adalah suatu prosedur untuk mencari hubungan antar item dalam suatu data set yang ditentukan. Association rule meliputi 2 tahap:

1. Mencari kombinasi yang paling sering terjadi dari suatu itemset;

2. Mendefinisikan condition dan result (untuk conditional association rule). 
Dalam menentukan suatu association rule, terdapat suatu interestingness meassure (ukuran kepercayaan) yang didapatkan dari hasil pengolahan data dengan perhitungan tertentu. Umumnya ada 2 ukuran yaitu:

1. Support adalah suatu ukuran yang menunjukkan seberapa besar tingkat dominasi suatu itemset dari keseluruhan transaksi. Ukuran ini menentukan apakah suatu itemset layak untuk dicari confidence-nya (misal, dari keseluruhan transaksi yang ada, seberapa besar tingkat dominasi item A dan B dibeli secara bersamaan). Nilai support sebuah item diperoleh dengan rumus berikut:

$$
\text { Support } A=\frac{\text { Jumlah transaksi Mengandung A }}{\text { Total Transaksi }} \times 100 \%
$$

Sedangkan nilai support dari 2 item diperoleh dari rumus berikut:

$$
\text { Support }(A \cap B)=\frac{\text { Jumlah transaksi mengandung A dan } B}{\text { Total Transaksi }} \times 100 \%
$$

2. Confidence adalah suatu ukuran yang menunjukkan hubungan conditional antar dua item (misal seberapa sering obat B dibeli jika orang membeli obat A). Nilai confidence dari aturan A B diperoleh dari rumus berikut:

$$
\text { Confidence }=P(B \mid A)=\frac{\text { Jumlah transaksi mengandung } A \text { dan } B}{\text { Transaksi mengandung } A} \times 100 \%
$$

\section{HASIL DAN PEMBAHASAN}

\subsection{Perancangan}

\subsubsection{Use Case Diagram}

Use case diagram merupakan diagram yang menggambarkan semua kasus (case) yang akan ditangani oleh perangkat lunak beserta aktor atau pelakunya. Rancangan sistem yang diimplementasikan dalam bentuk diagram UML (Unified Modeling Language). Pada Gambar 1 dapat dilihat perancangan atau kebutuhan sistem informasi penjualan yang digambarkan dalam bentuk use case diagram. 
Jurnal Pengembangan Sistem Informasi dan Informatika

Vol. 1, No. 3, July 2020 e-ISSN: 2746-1335

http://journal.jis-institute.org/index.php/jpsii/index

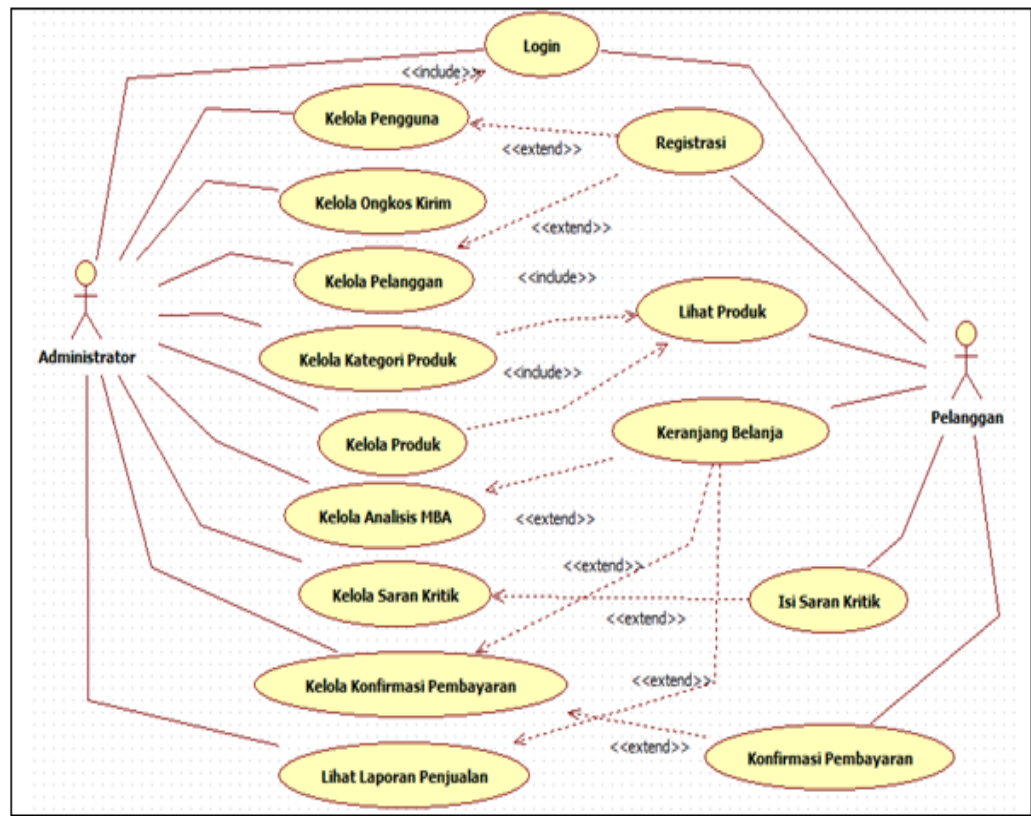

Gambar 1 Use Case Diagram

\subsubsection{Activity Diagram Pelanggan}

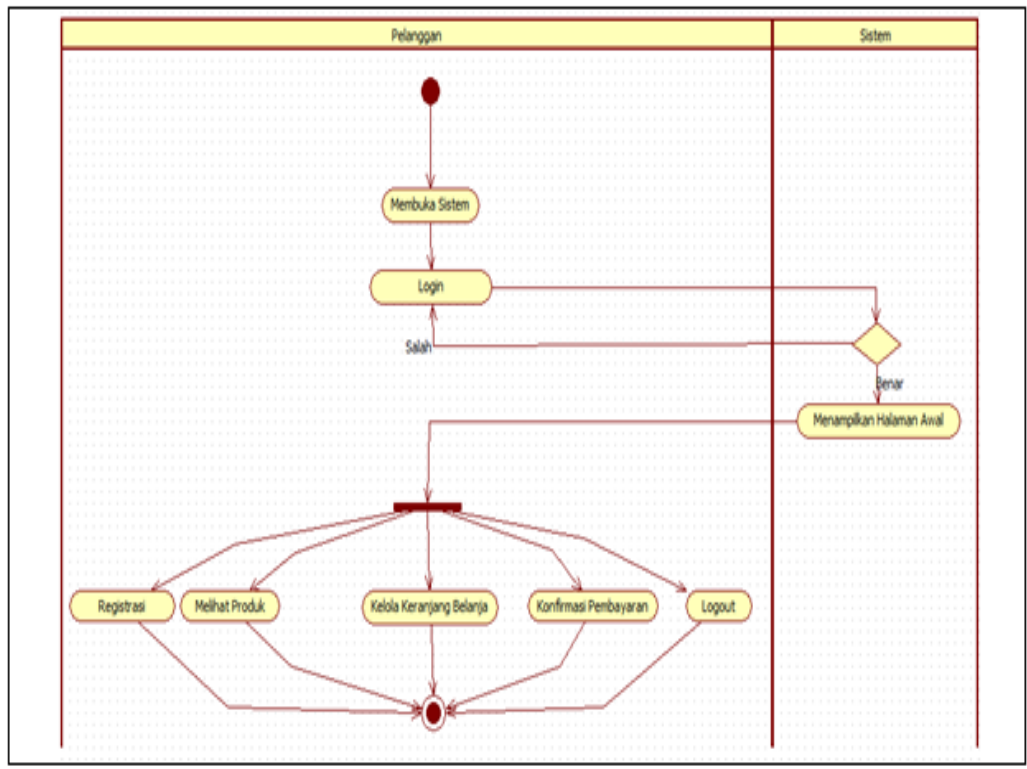

Gambar 2. Activity Diagram Pelanggan 


\subsubsection{Class Diagram}

Class Diagram adalah sebuah class yang menggambarkan struktur dan penjelasan class, paket, dan objek serta hubungan satu sama lain seperti containment, pewarisan, asosiasi, dan lain-lain. Class diagram juga menjelaskan hubungan antar class dalam sebuah sistem yang sedang dibuat dan bagaimana caranya agar dapat saling berkolaborasi untuk mencapai sebuah tujuan. Class merepresentasikan sesuatu yang ditangani oleh sistem.

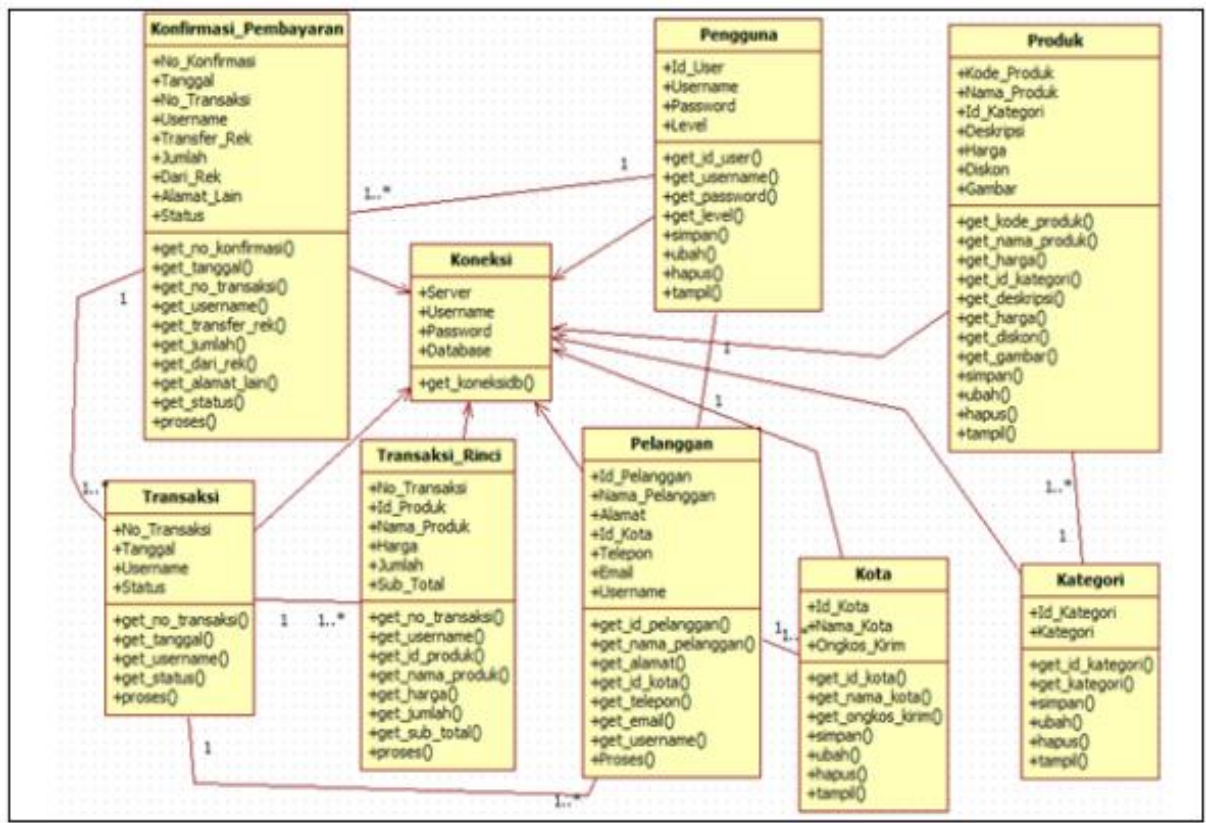

Gambar 3. Class Diagram

\subsection{Hasil Pengembangan}

Hasil yang didapatkan dari pengembangan Sistem penjualan berbasis online pada Butik Nazwa Fashion menggunakan metode Market Basket Analysis (MBA) adanya aktor yang menjalankan sistem sebanyak 3 aktor yang berhak mengakses sistem yaitu Admin, Pimpinan dan Pelanggan. Setiap pengguna memiliki hak akses masing-masing setiap hak akses dibuat dengan disesuaikan kebutuhan pengguna.

Impementasi sistem dilakukan oleh 3 aktor yang berhak mengakses sistem yaitu Admin, Pimpinan dan Pelanggan yang memiliki fungsi masing-masing. 


\section{Halaman Home}

Halaman Home merupakan Halaman awal yang tampil saat pengguna mengakses kedalam sistem website. Halaman Home terdapat menu - menu yang dapat dilihat oleh penguguna tannpa harus login, seperti Home, Profile, Produk Kami, Keranjang Belanja, Konfirmasi Pembayaran dan Hubungi Kami.

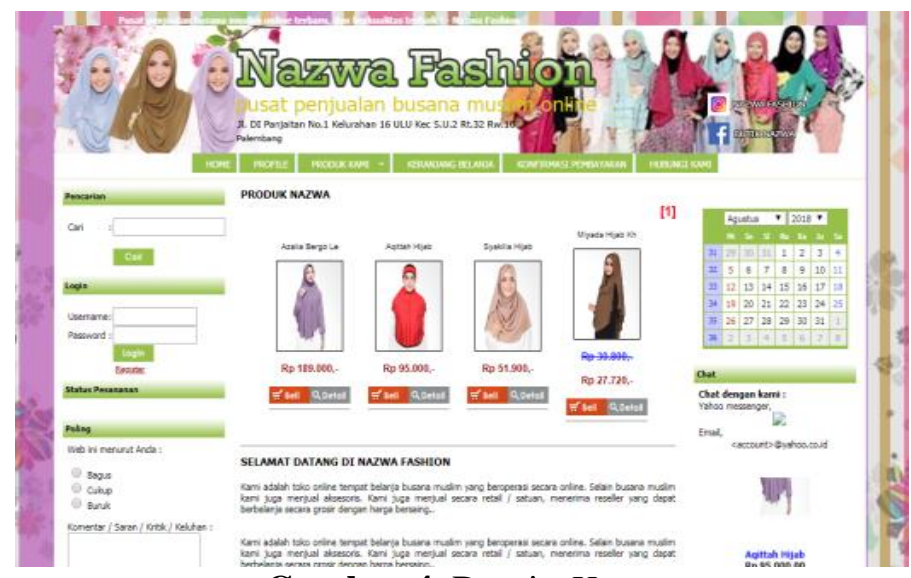

Gambar 4. Desain Home

\section{Halaman Profil}

Halaman Profil merupakan halaman yang akan menampilkan informasi gambar toko secara fisik beserta alamat.

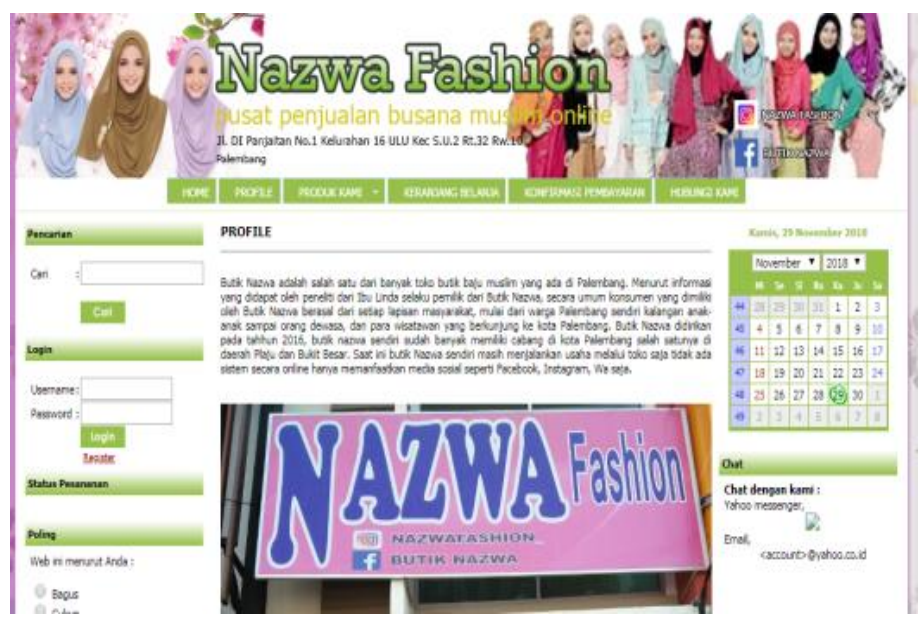

Gambar 5. Halaman Profil 


\section{Halaman Produk Kami}

Halaman Produk Kami akan menampilkan informasi produk yang dimiliki perusahaan secara keseluruhan atau perkategori produk.

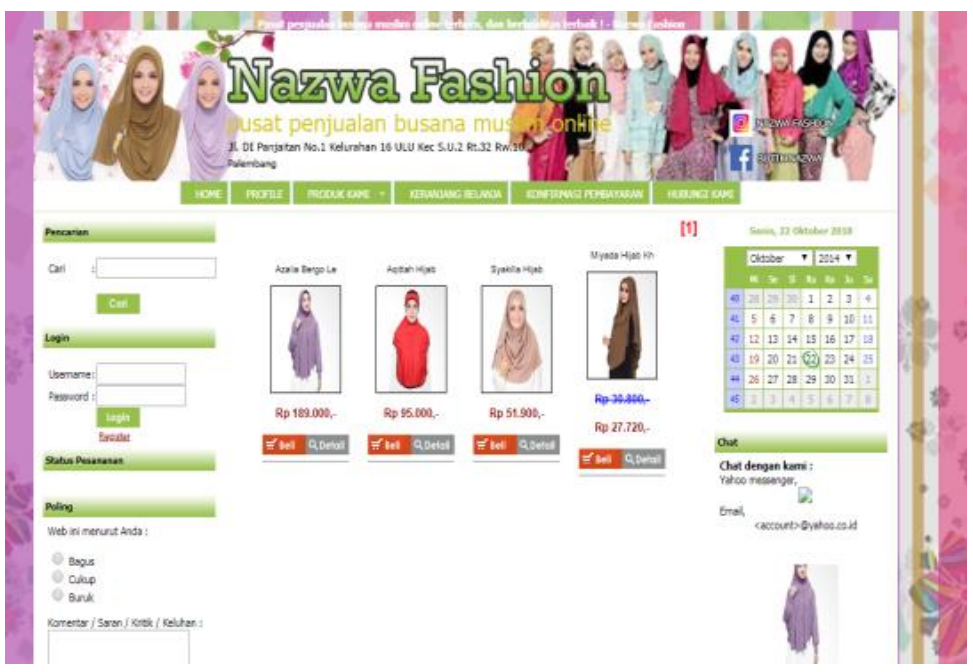

Gambar 6. Halaman Produk Kami

\section{Halaman Keranjang Belanja}

Halaman Keranjang Belanja berfungsi untuk menampilkan informasi daftar produk belanja yang Anda pilih, barang yang dipesan akan tampil di halaman ini.

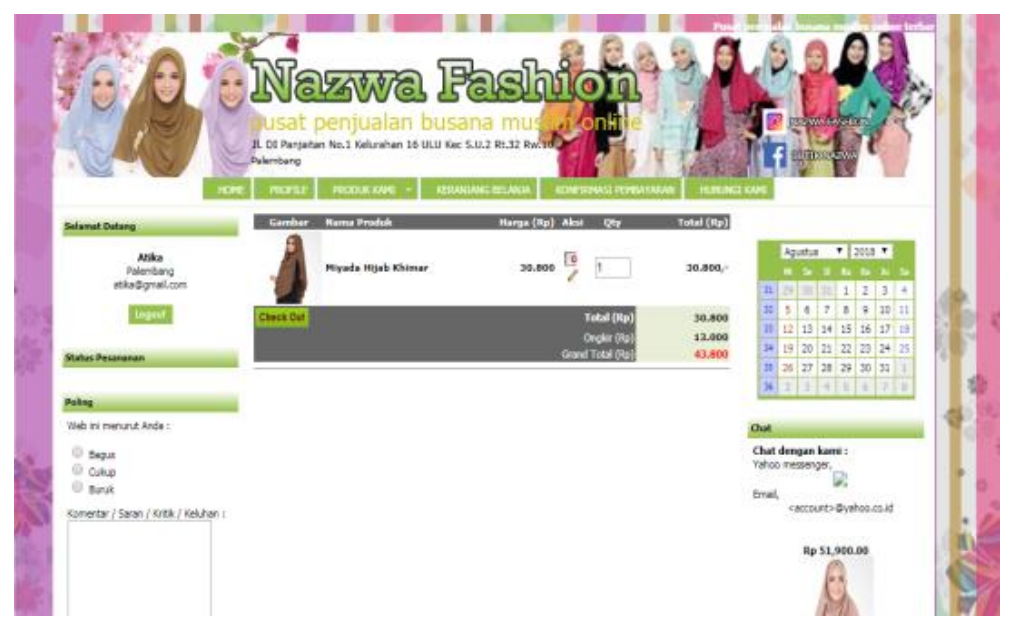

Gambar 7. Halaman Keranjang Belanja 


\section{Halaman Konfirmasi Pembayaran}

Halaman Konfirmasi Pembayaran digunakan untuk pelanggan melakukan konfirmasi pembayaran atas pesanan yang telah dilakukan.

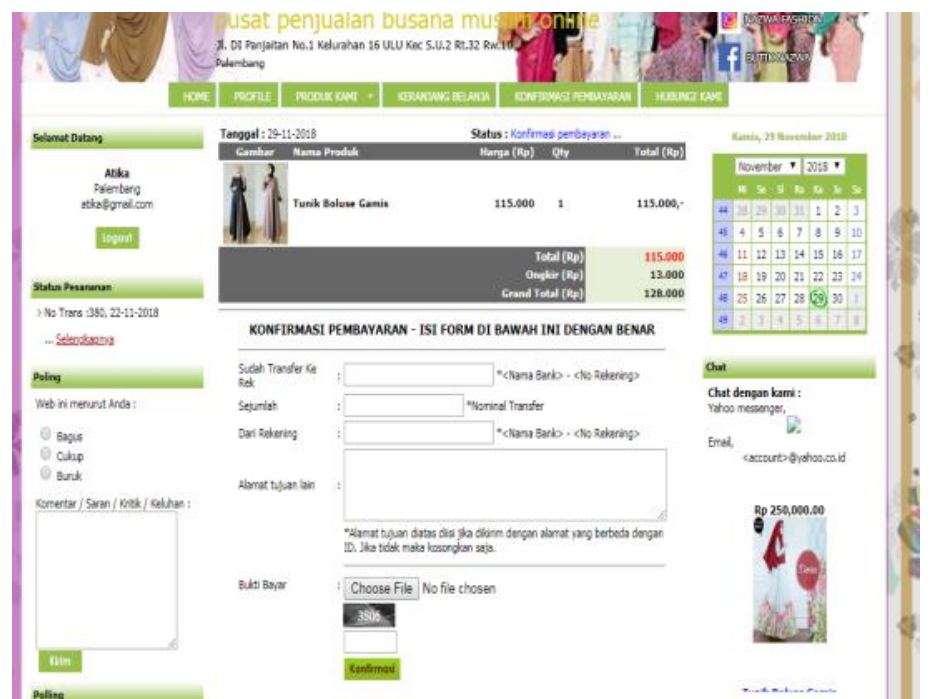

Gambar 8. Halaman Konfirmasi Pembayaran

\section{Halaman Hubungi Kami}

Halaman Hubungi Kami akan menampilkan informasi alamat perusahaan.

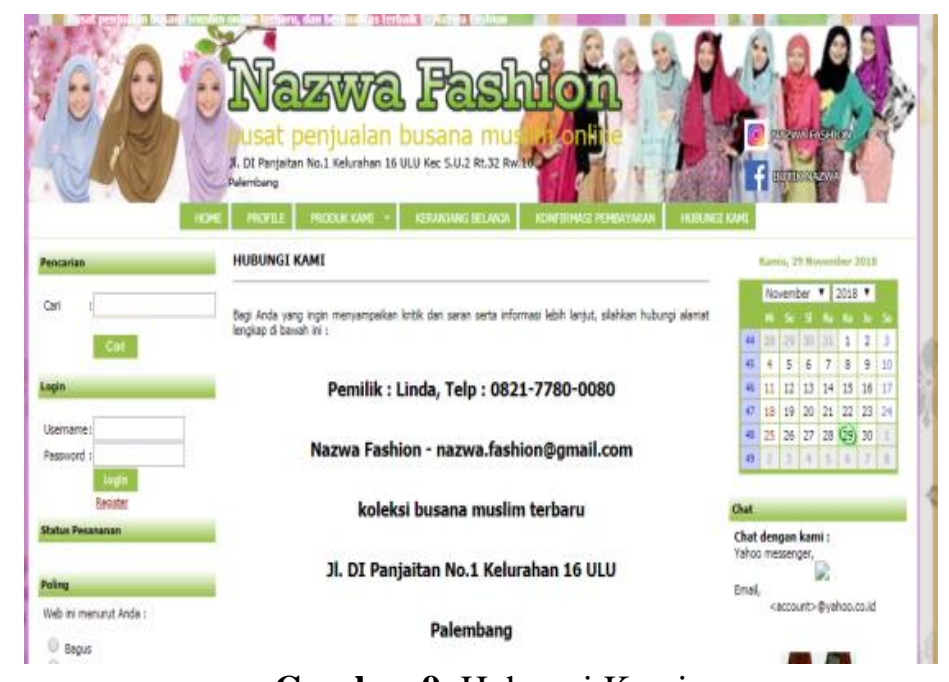

Gambar 9. Hubungi Kami 


\section{Halaman login Admin}

Halaman Login akan tampil pertama kali jika pengelola sistem masuk ke dalam sistem.

\section{Login}

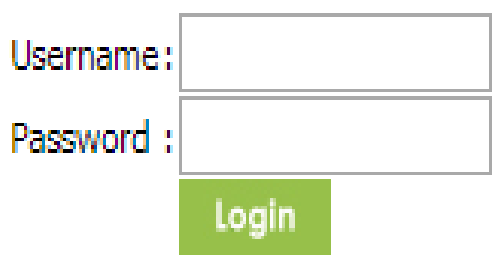

Register

\section{Gambar 10 Login Admin}

\section{Halaman Home Admin}

Halaman Home admin akan tampil pertama setelah sales counter berhasil login Untuk halaman Home admin.

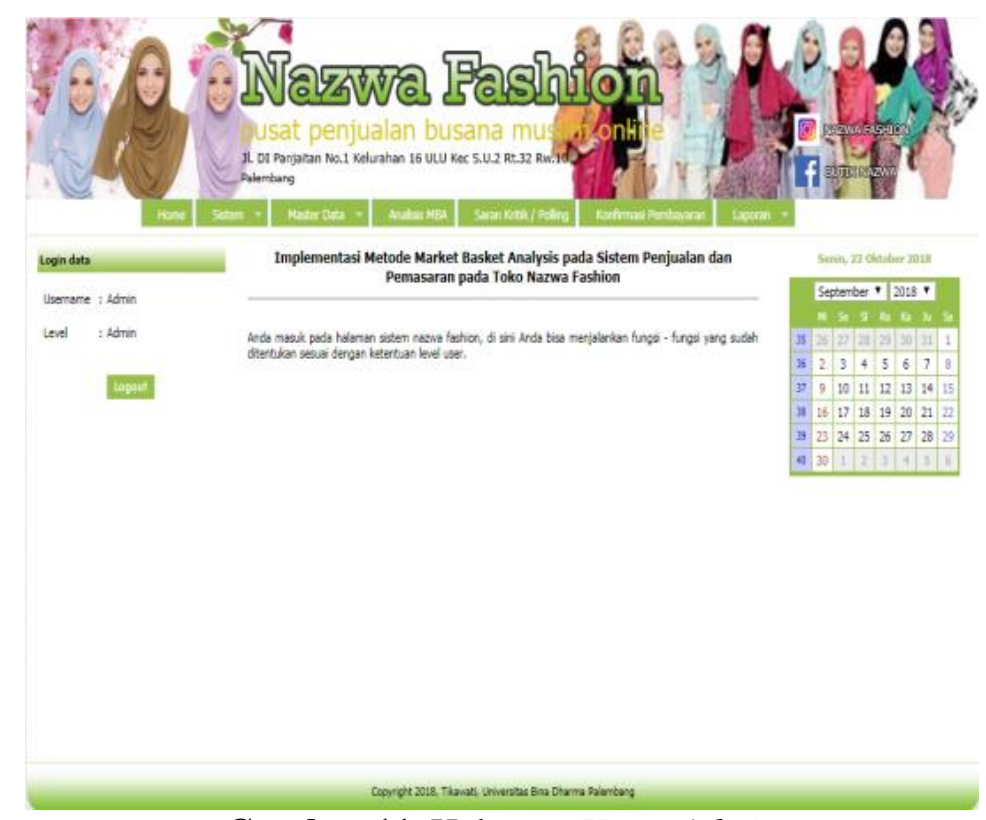

Gambar 11. Halaman Home Admin 


\section{KESIMPULAN}

Adapun kesimpulan dari penelitian mengenai Implementasi Metode Market Basket Analysis pada Sistem Penjualan dan Pemasaran pada Butik Nazwa Fashion dalam menghitung ulang jumlah persentase barang pemasukan dan pengeluaran stok barang yang ada di gudang.

1. Dalam membangun website E-Commerce pada Butik Nazwa Fashion akan dapat membantu sistem pemasaran dalam menjualkan barang, sehingga konsumen dapat melihat langsung barang yang dibeli tanpa harus datang ke toko.

2. Sistem website E-Commerce dengan metode Market Basket Analysis $(M B A)$ mampu mengetahui jumlah barang yang sangat tinggi penjualannya sehingga dapat meningkatkan lagi penjualan barang yang kurang diminati berdasarkan hasil laporan pada sistem website ECommerce.

3. Dengan menerapkan metode Market Basket Analysis (MBA) yang dapat membantu butik Nazwa Fashion dalam mengetahui jumlah stok barang yang terjual ataupun yang belum laku terjual.

\section{DAFTAR PUSTAKA}

Ardhana. Kusuma. (2014). Pemograman PHP: CodeIgniter Black Box. Informatika Bandung.

Furqon, Ali. (2013). Perancangan Aplikasi Sistem Informasi Penjualan Berbasis Microsoft Access 2007 pada Toko Syafa Collection, Laporan Akhir Politeknik Negeri Sriwijya.

Hakim, L., (2014). Proyek Website Super WOW dengan PHP dan jQuery. Lokomedia:Yogyakarta.

Han, Jiawei \& Kamber, Micheline. (2001). Data Mining:Concepts and Techniques, Morgan Kaufmann.

Kotler, Philip. (2009). Manajemen Pemasaran. Erlangga:Jakarta.

Kenneth, Laudon C. (2007). Sistem Informasi Manajemen. Edisi ke-10. Terjemahan Chriswan Sungkono dan Machmudin Eka P. Salemba Empat:Jakarta.

Nugroho, Bunafit. (2014). Panduan Proyek Membuat Website Toko Online dengan PHP, MySQL dan Dreamweaver. PT. Alif Media:Yogyakarta.

Pressman, Roger. (2001). Software Engineering: A Practitioner's Approach. Fifth Ed. New York: McGraw-Hill Book Company.

Pratama. I Putu Agus E. (2014). Sistem Informasi dan Implementasinya. Informatika:Bandung. 
Rosa \& Shalahuddin. (2011), Rekayasa Perangkat Lunak: Terstruktur dan berorientasi objek. Modula:Bandung.

Sutabri, Tata. (2012). Analisis Sistem Informasi. Andi:Yogyakarta.

Sugiyono. (2013). Metode Penelitian Kuantitatif, Kualitatif dan R\&D. CV. Alfabeta:Banndung.

Muzakir, Ari. (2014). Market Basket Analysis pada situs web E-commerce Zakiyah Collection. Jurnal SIMETRIS, Vol 7 No 2 November 2016 ISSN: 2252-4983.

Umar, Rusyidi \& Putri, Rizka Iromas. (2015). Pengembangan E-Commerce yang terintegrasi dengan Market Basket Analysis, Jurnal PROSIDING SENTRINOV Vol. 001, Tahun 2015, ISSN: 24772097. 